\title{
ADVANCED OXYFUEL BOILERS AND PROCESS HEATERS FOR COST EFFECTIVE CO 2 CAPTURE AND SEQUESTRATION
}

\section{ANNUAL TECHNICAL PROGRESS REPORT}

For Reporting Period Starting January 1, 2002 and Ending December 31, 2002

\section{Principal Authors:}

Program Manager and Business Officer: David R. Thompson

Principal Investigator, Combustion Development: Lawrence E. Bool

Principal Investigator, OTM Development: G. Maxwell Christie

Report Issue Date: July 2003

DOE AWARD NO. DE-FC26-01NT41147

Submitted by:

Praxair, Inc.

175 East Park Drive

Tonawanda, NY 14150 


\section{DISCLAIMER:}

This report was prepared as an account of work sponsored by an agency of the United States Government. Neither the United States Government nor any agency thereof, nor any of their employees, makes any warranty, express or implied, or assumes any legal liability or responsibility for the accuracy, completeness, or usefulness of any information, apparatus, product, or process disclosed, or represents that its use would not infringe privately owned rights. Reference herein to any specific commercial product, process, or service by trade name, trademark, manufacturer, or otherwise does not necessarily constitute or imply its endorsement, recommendation, or favoring by the United States Government or any agency thereof. The views and opinions of authors expressed herein do not necessarily state or reflect those of the United States Government or any agency thereof.

\section{ABSTRACT:}

This annual technical progress report summarizes the work accomplished during the first year of the program, January-December 2002, in the following task areas: Task 1 - Conceptual Design, Task 2 - Laboratory Scale Evaluations, Task 3 - OTM Development, Task 4 - Economic Evaluation and Commercialization Planning and Task 5 - Program Management.

The program has experienced significant delays due to several factors. The budget has also been significantly under spent. Based on recent technical successes significant future progress is expected.

A number of concepts for integrating Oxygen Transport Membranes (OTMs) into boilers and process heaters to facilitate oxy-fuel combustion have been proposed. A detailed modeling plan has been proposed and early modeling work has focussed on developing spreadsheet based models for quick engineering calculations.

Combustion reactor laboratory scale evaluations efforts have been delayed due to the closing of Praxair's Tarrytown facility in December 2001. Experimental facilities and personnel have been relocated to Praxair's facility in Tonawanda. The facilities have recently been re-commissioned.

Work with the OTM development task has also been delayed as early material selections were discarded. More recently, more promising OTM material compositions have been identified.

Economic evaluation commenced. Information was acquired that quantified the attractiveness of the advanced oxygen-fired boiler. $\mathrm{CO}_{2}$ capture and compression are still estimated to be much less than $\$ 10 /$ ton carbon. 


\section{TABLE OF CONTENTS}

A. EXECUTIVE SUMMARY ...............................................................................................................................................

B. EXPERIMENTAL .......................................................................................................................................................................................4

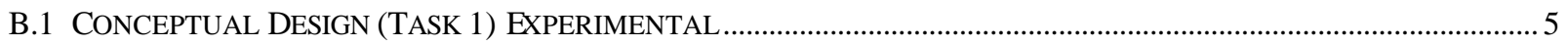

B.2. LABORATORY SCALE EVALUATION (TASK 2) EXPERIMENTAL …………………………………………………... 6

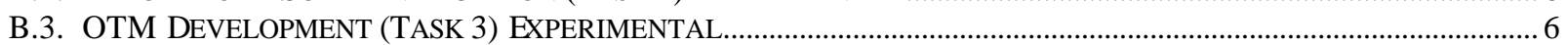

C. RESULTS AND DISCUSSION ..........................................................................................................................................................

C.1. CONCEPTUAL DESIGN (TASK 1) RESUlTS AND DISCUSSION ................................................................................ 8

C.2. LABORATORY SCALE EVALUATIONS (TASK 2) RESULTS AND DISCUSSION ………………….................................11

C.3. OTM DEVELOPMENT (TASK 3) RESULTS AND DISCUSSION................................................................................ 11

C.4. ECONOMIC EVALUATION AND COMMERCIALIZATION PLANNING (TASK 4) RESULTS AND DisCUSSION............. 12

C.5. PROGRAM MANAGEMENT (TASK 5) RESULTS AND DISCUSSION …………………………………………....... 13

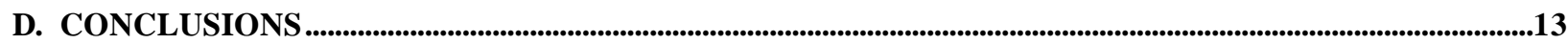

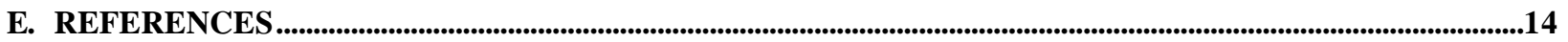




\section{A. Executive Summary}

The primary objective of this program is to determine the feasibility of integrating Oxygen Transport Membranes into combustion processes such as industrial boilers and process heaters. The aim is to develop a novel oxy-fuel combustion processes that will significantly reduce the complexity of $\mathrm{CO}_{2}$ capture, reduce the cost of carbon sequestration to less than $\$ 10 /$ ton. Even without $\mathrm{CO}_{2}$ capture the oxy-fuel process offers increased thermal efficiency and reduced pollution emissions.

The breakdown of the program work consists of the following five major tasks:

Task 1. Conceptual Design

Task 2. Laboratory Scale Evaluation

Task 3. OTM Development

Task 4. Economic Evaluation and Commercialization Planning

Task 5. Program Management

Task 1 work is focused on developing conceptual designs for industrial boilers. A number of design concepts have been generated during the first year of the program. The developed concepts can be broadly classified as reactive purge, in which the OTM elements are directly exposed to combustible fuel species and inert purge, in which the OTM elements are only exposed to the flue gas.

Modeling tools are used to aid in the evaluation of the proposed concepts and a detailed model development plan has been drawn-up. To date, a spreadsheet-based combustion model has been developed. The spreadsheet-based module provides design engineers with a tool that enables them to estimate net radiative heat fluxes to tube walls, a simple gas emissivity module has also been incorporated. Example calculations are included in this report.

Combustion reactor laboratory scale evaluations (Task 2) efforts were delayed due to the closing of Praxair's Tarrytown facility in December 2001. The combustion testing facilities were moved to Praxair's Tonawanda site in 2002 and have only recently been re-commissioned.

Oxygen transport membrane (OTM) development work in this program (Task 3) is also delayed. The original OTM material selections were discarded. As of Q1, 2003 new candidate materials were identified that show sufficient promise in other OTM applications to be considered as candidates for the OTM "Integrated Combustion" application. Going forward these new materials shall become the principal candidate OTM materials for this application.

A number of the integrated OTM / combustion concepts require somewhat different membrane configurations from those that have been previously manufactured. Experiments were performed with a novel fabrication method better suited for manufacturing complex OTM shapes. Optimization of OTM material and system will continue in the second year of this program. 
Economic evaluation (Task 4) commenced. Information was acquired that quantified the attractiveness of the advanced oxygen-fired boiler. $\mathrm{CO}_{2}$ capture and compression are still estimated to be much less than $\$ 10 /$ ton carbon.

\section{B. Experimental}

Praxair will develop and demonstrate the integration of novel ceramic Oxygen Transport Membranes (OTMs) in a combustion process in order to enhance boiler or process heater efficiency and facilitate carbon dioxide recovery. Praxair's integrated combustion concept (Figure 1) integrates air separation using OTMs directly with the combustion process. The integrated combustion concept uses the chemical potential difference of the combustible species and air as the driving force for air separation at high temperatures using OTMs.

Also, the integrated combustion concept results in flue gas containing only $\mathrm{CO}_{2}, \mathrm{H}_{2} \mathrm{O}$ and a limited amount of inert gas $\left(\mathrm{N}_{2}\right)$ that was contained in the starting fuel, hence the flue gas can be readily processed to facilitate $\mathrm{CO}_{2}$ separation and subsequent sequestration.

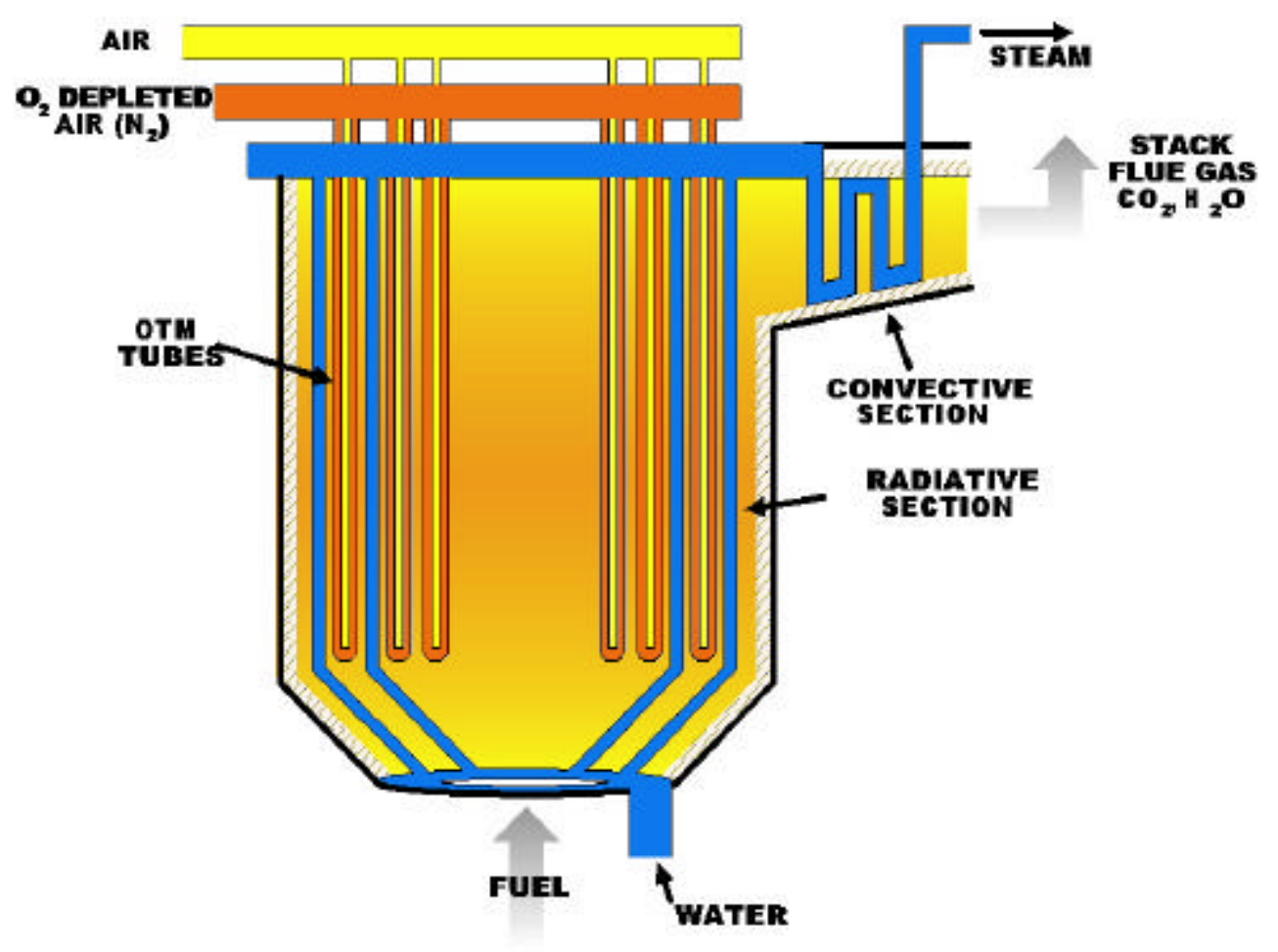

$\underline{\text { Figure 1. Praxair Integrated Combustion Concept }}$ 


\section{B.1 Conceptual Design (Task 1) Experimental}

The objective of this task is to develop conceptual designs for integrating (Oxygen Transport Membrane s) OTMs in boilers and process heaters to facilitate economic oxy-fuel combustion.

During this reporting period, a comprehensive modeling plan has been developed to address the specific modeling requirements of this program ${ }^{1}$. This modeling plan is being executed and consists of three essential components as described below.

\section{B.1.1 Development of Spreadsheet Modules for Quick Engineering Calculations}

The purpose of this subtask is to develop spreadsheet modules that can be used for estimating radiative heat fluxes to various surfaces including tube walls. These relatively simple modules are spreadsheet based. Thermal enclosures that are common to high temperature combustion processes as well as enclosures specific to the OTM boiler are considered.

High temperature thermal enclosures typically consist of heat absorbing, heat reflecting, and heat radiating surfaces as well as hot combustion gases. Development of the spreadsheet module will provide design engineers with a tool that will enable them to quickly estimate net radiative heat fluxes to tube walls based on known or estimated ranges of design variables. A simple gas emissivity module will also be incorporated to provide greater flexibility and utility of the spreadsheet module.

\section{B.1.2 Development of a 2D Boiler Model for Rapid Concept Screening Analysis}

This subtask aims to develop a two-dimensional OTM boiler model for rapid screening of various advanced integrated combustion concepts. This new OTM boiler model will be developed on the basis of a validated in-house boiler model, written in Fortran and running on a PC. The availability of this model will enhance the ability to predict the effect of various OTM and steam/water tube arrangements on the performance of boilers or process heaters that are axisymmetric in geometry.

The existing boiler model can predict many aspects of furnace radiative heat transfer and is a simplified version of a more detailed three-dimensional combustion model. A major strength of the model is that the numerical method used for the radiation calculations is unique and it enables the model to handle very complicated boundary conditions. This feature fits well with Praxair's OTM integrated combustion concept, since the new boilers or process heaters are expected to be filled with steam/water tubes and OTM tubes which makes radiative heat transfer calculations difficult and complex.

However, the existing combustion model was developed for conventional boilers or process heaters and therefore modifications to the model are required to describe the new process components properly. In particular, the existing model needs to be modified for the new mode of oxygen distribution and fuel combustion. This modification will be carried out in a way that the 
resulting model resolution is fine enough to capture the model's predictive value but not become too intricate and lose the capability for rapid screening.

\section{B.1.3 Detailed Analysis Using the Most Advanced Commercial CFD Software}

A general purpose CFD (computational fluid dynamic) computer model (CFX) developed and marketed by AEA Engineering Software Inc. will be applied to selected model cases that represent the most promising OTM integrated combustion concepts identified. One major purpose of this modeling subtask is to recognize potential operating challenges and suggest improvement or design options prior to the concepts are finalized, or to the commitment of significant resources to demonstration of the technology.

This subtask will also require the development and integration of subroutines necessary to describe the combustion and transport processes occur at and near the OTM tubes.

\section{B.2. Laboratory Scale Evaluation(Task 2) Experimental}

The experimental work to be carried out within this task involves the design, construction and commissioning of both single and multi-tube reactors that simulate environments likely to be experienced by the OTM tubes in the integrated combustion application. Once commissioned, the reactors will be used both to validate computer models and to ultimately qualify OTM materials and modules and elements of the proposed conceptual designs.

It was anticipated that the first experiments would use porous tubes in place of OTM elements. The viscous flow of oxygen through the porous tubes would be controlled to simulate oxygen permeation through OTM tubes. Temperature management of the OTM tube is complex and critical, combustion stability, pollutant formation and heat transfer issues will be evaluated.

As promising OTM candidate materials are identified (see B.3. Task 3, OTM development), larger scale OTM tubes or tube-modules will be substituted for the porous tubes in the laboratory scale reactors. OTM performance, stability and ability to withstand thermal and chemical cycles in an actual combustion environment will also be evaluated. It is important to demonstrate that the ceramic OTM elements are sufficiently robust in laboratory scale tests before moving forward with technology demonstration.

\section{B.3. OTM Development (Task 3) Experimental}

The experimental work to be performed within this task involves the selection and characterization of candidate OTM materials for the OTM tubes or tubes modules of the advanced boiler. Oxygen fired boilers or process heaters present challenging materials environments. To be commercially viable the boiler or process heater OTM elements must be mechanically and chemically robust and maintain high oxygen conductivity for long periods of time (>10 years) under harsh conditions. 
Aside from the magnitude of oxygen flux through the membrane, important materials parameters that have to be considered during the materials selection process are:

- Phase stability

- Thermal expansion

- Chemical expansion

- Mechanical stability

- Corrosion resistance and compatibility with boiler materials of construction

ANSYS modeling of conceptual designs shall be used to define targets and convention material characterization techniques along with available public and confidential Praxair data shall be used to aid in the material selection process.

After candidate materials have been selected the membrane materials shall be manufactured into tubes or tube-bundles that are comprised of dense films of the OTM material supported on porous substrates. The porous substrate must have compatible thermal and chemical expansion with the OTM film but need not necessarily be the same material. 


\section{Results and Discussion}

\section{C.1. Conceptual Design (Task 1) Results and Discussion}

A number of preliminary design concepts have been proposed, broadly classified as either reactive or inert purge $^{2}$ (see figure 2 ).
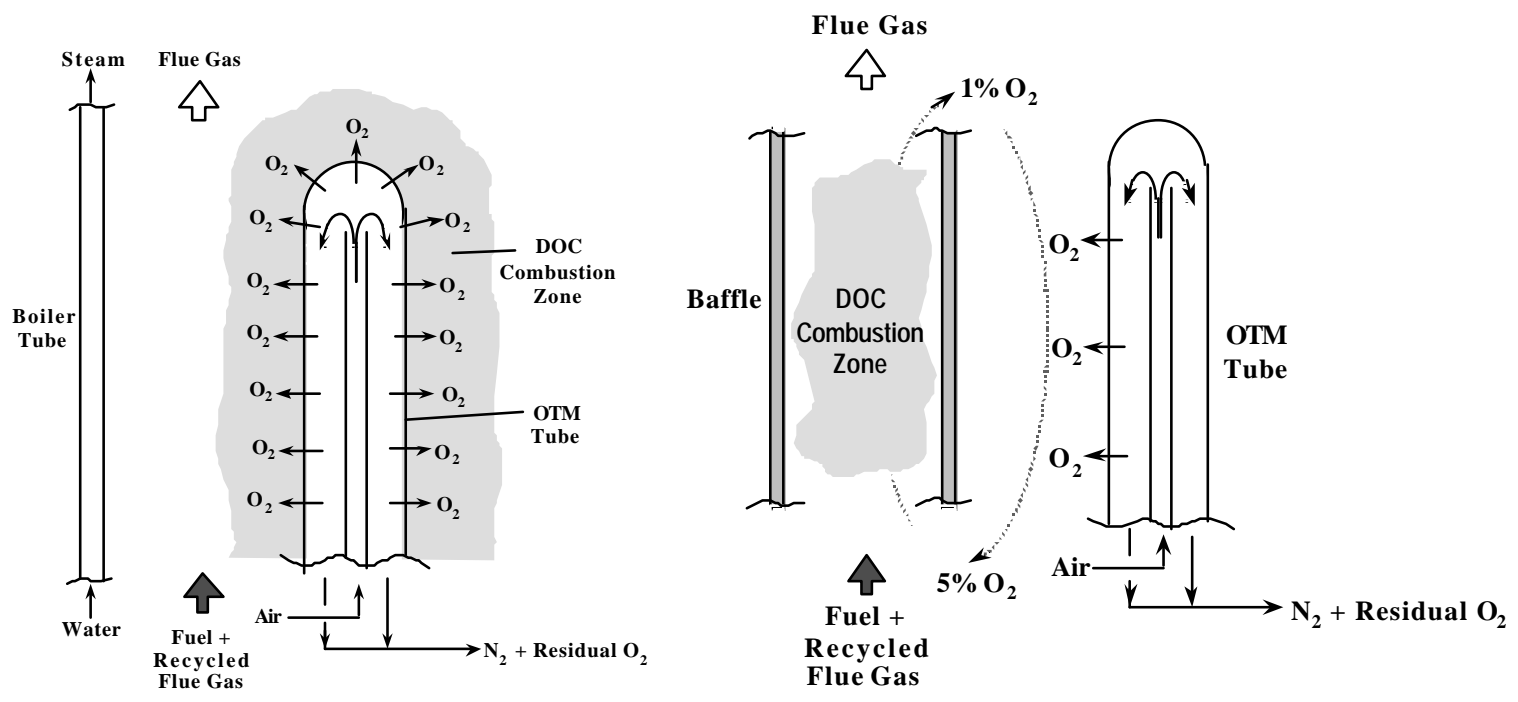

Figure 2. Schematic of the reactive gas purge (left) and inert gas purge (right) boiler concepts.

Reactive purge designs directly expose the OTM to combustible fuel species, while inert purge designs only expose the OTM to the flue gas. Quantitative evaluations of the overall heat and mass balances for these concepts are ongoing. To aid in the evaluation of these conceptual designs, a spreadsheet-based model has been developed to estimate radiative heat fluxes for various advanced boiler geometry and operating conditions as described in detail below. A robust gas emissivity estimator was also developed to increase the flexibility and utility of the model, also described below.

Mathematical modeling of the OTM boiler has focused on developing spreadsheet modules for quick engineering calculations. This work is the first task of the three-component modeling approach, described in Section B This section describes spreadsheet modules that have been developed under this program for engineering estimation of radiative heat fluxes. The ability to quickly estimate radiative heat fluxes is believed to be important and can contribute to the initial conceptual development of the OTM boiler. For example, if the net radiative heat flux to a specified surface sink is known, then it can be used to estimate the cooling requirement of the surface. The cooling requirement would in turn affect other furnace design concepts since the temperature of the surface sink needs to be maintained below a maximum allowable value.

Figure 3 lists some radiation configurations currently considered in the radiation spreadsheet modules. These configurations are further classified into two groups depending on whether or 
not emissive gases participate in the radiation calculation. Once a configuration is identified, the spreadsheet module calculates net radiative heat fluxes to each surface based on user's inputs of furnace operating conditions. The list of radiation configurations would be expanded in the future to include furnace arrangements resulting from other program tasks.

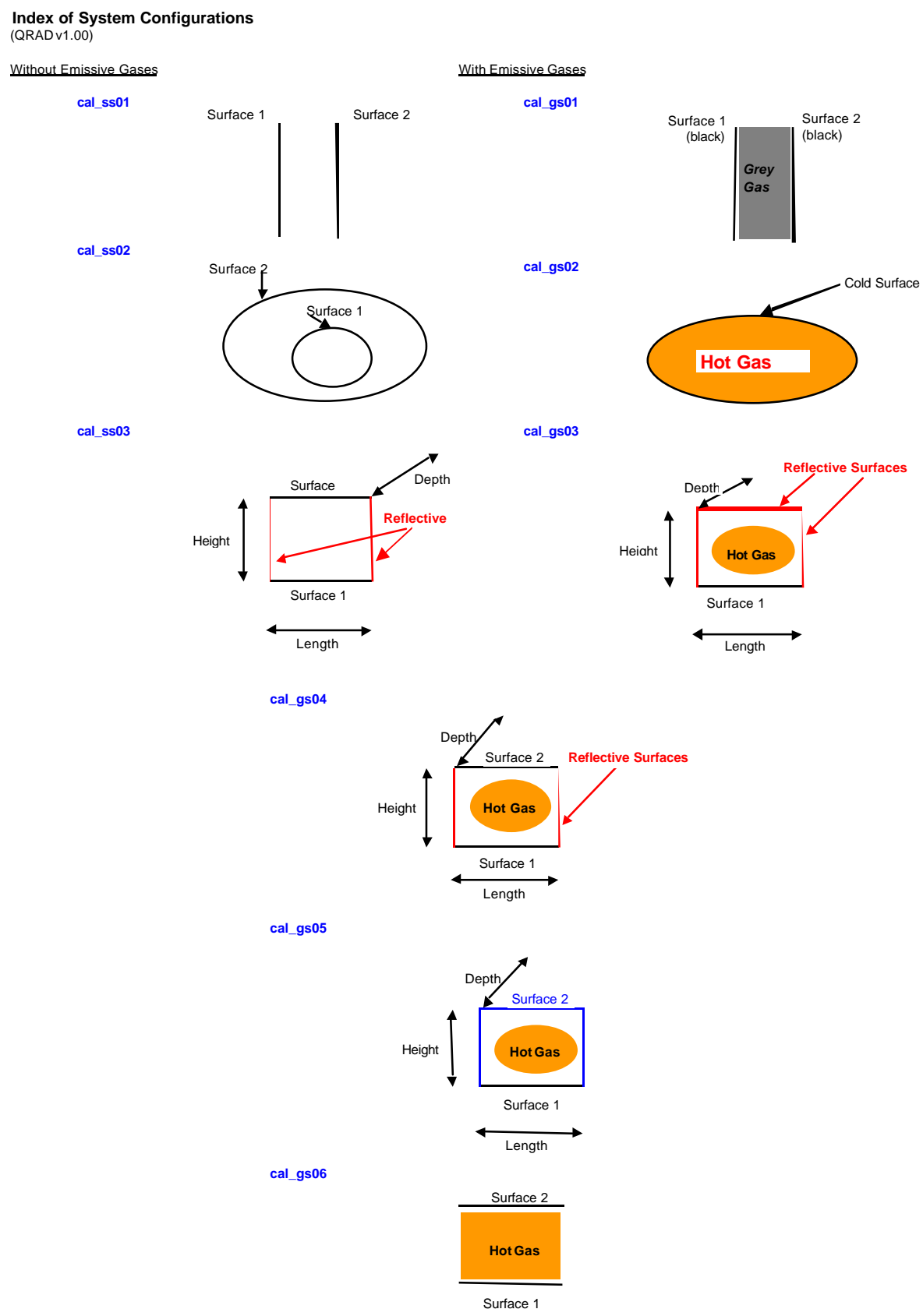

Figure 3. Radiation configurations considered by the spreadsheet module 
Figure 3 demonstrates the usefulness of the radiation spreadsheet module by using a furnace condition involving hot combustion gases, refractory walls, and rows of tubes as heat sinks. The spreadsheet module properly accounts for multiple radiation-beam reflections and absorptions by participating mediums within the furnace enclosure.

The furnace is assumed to have a dimension of $1 \mathrm{~m} \times 1 \mathrm{~m} \times 3 \mathrm{~m}$, the diameter of the heat absorbing tubes is 1 inch and the tube pitch is 2, the temperature of the hot combustion gas $\left(60 \% \mathrm{H}_{2} \mathrm{O}\right.$ and $30 \% \mathrm{CO}_{2}$ ) is $2000 \mathrm{~K}$ and the maximum allowable OTM tube surface temperature is $1100^{\circ} \mathrm{C}$. For the purposes of this example, the high-temperature emissivity of the OTM tube has been assumed to be 0.36 . This tube emissivity assumption can obviously severely impact results and the therefore the usefulness of the model. As the OTM materials are further down-selected and refined, more accurate estimations of high temperature emissivity will be developed. The emissivity of the hot gas is evaluated in a separate module described later in Figure 5.

Calculated radiative heat fluxes from a hot combustion gas to one-row of OTM tubes or two rows of OTM tubes are displayed in the boxed area in various units. It is worthwhile to mention that for a two-row tube configuration, the calculated results show much less heat flux to the second-row tubes. It should be noted that the examples provided are only to demonstrate the workings of the model and do not necessarily reflect any of Praxair's integrated combustion concepts at this stage.

Type_GS07 : Hot gas completely enclosed by reflective surfaces; tube banks (one or two rows) absorb heat; 3D geometry (QRAD v1.00)

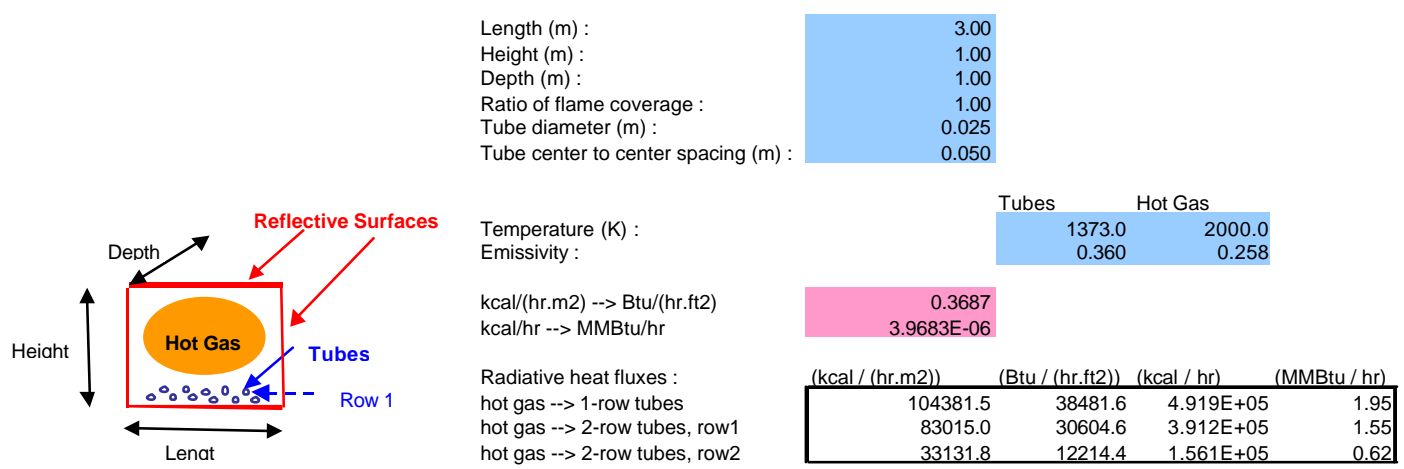

Figure 4. Example of Spreadsheet modules for estimation of radiative heat fluxes

Figure 5 shows results from the developed gas emissivity module. In this example, the module calculates and displays the total emissivity of a combustion gas stream containing carbon dioxide and water vapor under the set of furnace conditions specified in Figure 4. This gas emissivity module has been shown to be more accurate than the widely used $\mathrm{CO}_{2}$ and $\mathrm{H}_{2} \mathrm{O}$ emissivity charts and can be applied to a wide range of combustion conditions, for instance, at furnace pressures much greater than 1 atmosphere. 


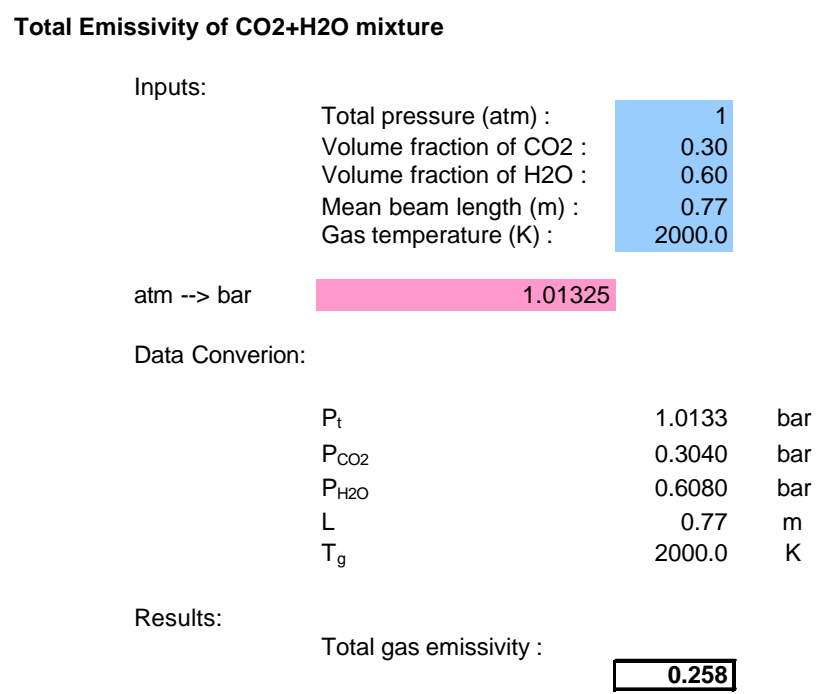

Figure 5. Example of results from the developed flame emissivity module

\section{C.2. Laboratory Scale Evaluations (Task 2) Results and Discussion}

It was originally planned that the laboratory scale evaluation task would commence with porous tubes replacing OTM tubes in oxy-fuel combustion tests. This work was originally scheduled to be carried out in Praxair's Tarrytown, NY facility. The Tarrytown facility was closed in December 2001 and personal and experimental facilities were transferred to the Praxair Technology Center in Tonawanda, NY during 2002. Hence there has been a substantial delay in progress against this task. The combustion facilities have been reassembled and work is scheduled to commence towards the later half of 2003.

There are existing facilities that require some modification for testing OTM tubes in simulated combustion environments at Praxair's facility in Tonawanda, however this work has also been delayed for reasons outlined below (C.3. OTM development).

\section{C.3. OTM Development (Task 3) Results and Discussion}

The OTM material selection and characterization task was kicked-off in the fall of 2002. Four OTM candidate materials, designated PXAB2, PXAB4, PBAX5 and PXAB6, were selected for further evaluation as candidates for the integrated combustion application.

Soon after work commenced, a number of serious shortfalls were identified with the selected materials as they were being evaluated for use in other OTM applications in parallel OTM development programs at Praxair and Praxair's partners. The selected materials were then discarded as candidate OTM materials for integrated combustion. As opposed to committing a great deal of the available resource to the task of developing new materials specifically within this program, a decision was made to place the task on hold. Work on OTM materials development continued in parallel programs at Praxair and Praxair's partners. 
As of Q1, 2003 new candidate materials have been identified that show sufficient promise in other OTM applications to be considered as candidates for the OTM integrated combustion application. Creep rates have been reduced over 100x and fracture toughness has been improved over 5x. Going forward these new materials shall become the principal candidate OTM materials for this application.

A number of the boiler concepts, defined in task 1, require somewhat different membrane configurations from those that have been previously manufactured. A novel ceramic fabrication method, better suited to complex shapes has been identified and work proceeded in determining the feasibility of this new manufacturing technique ${ }^{3}$. Experiments were initially carried out with ceramic discs in order to define the ideal processing parameters. Enough work has been completed to date to justify experimenting with production of tubular structures. Single tubes as well as more intricately shaped elements developed in another program were studied. The majority of the experimental work used alumina as the base powder. Initial results show the techniques are likely to translate to other powders with little, if any, modification. Optimization of OTM material and system will continue in the second year of this program.

\section{C.4. Economic Evaluation and Commercialization Planning (Task 4) Results and Discussion}

On going cost analysis continues to indicate the economic attractiveness of the advanced boiler.

- Efficiency improvements of $14 \%$

- For a 100,000 lb/hr @ \$3/MMBTU energy savings are $\$ 450,000 / \mathrm{yr}$

- $\mathrm{CO}_{2}$ emissions reductions are $\sim 8$ million $\mathrm{kg} / \mathrm{yr}$

- Based on current boiler costs, the energy savings cover the cost in <2 years

- The expected incremental cost of the integrated boiler should also be paid for in less than 2 years. Work to better understand the cost of an OTM boiler is ongoing.

- $\mathrm{CO}_{2}$ capture and compression costs are also being reviewed

On a larger scale based on a $20 \%$ boiler conversion over 10 years

- Annual US savings over $\$ 600$ million/yr are estimated.

- $\mathrm{CO}_{2}$ reductions with no sequestration are estimated at $1.10 \times 10^{10} \mathrm{~kg} / \mathrm{yr}$.

- Estimated cost of carbon and compression significantly less than $\$ 10 /$ ton. 


\section{C.5. Program Management (Task 5) Results and Discussion}

The Program Management highlights for this US DOE Advanced Oxyfuel Boiler program are as follows:

- The program kick-off meeting was held November 20, 2001 at the US DOE facility in Pittsburgh, PA.

- An update meeting was held on August 16, 2002 at the Praxair Tonawanda, NY facility.

- Accounts were established within the Praxair accounting system to track labor hours and costs. Monitoring of these accounts was ongoing.

- Project documentation has been prepared and delivered to the US DOE in accordance with the cooperative agreement including the Petition for Advance Waiver of Patent, Hazardous Substance Plan, quarterly technical highlights/update reports and quarterly financial status reports.

- The program spending is substantially under budget.

\section{Conclusions}

Although preliminary conceptual designs have been proposed and modeling work has been initiated, limited progress was made this year toward achieving the program objectives, whilst substantially under-spending the budget.

Progress was limited as Praxair's Tarrytown, NY facility was shut-down and relocated to Tonawanda during 2002. This clearly caused a major set-back in the program. Furthermore the initial OTM materials selected failed to live up to expectations in other programs and OTM materials development was put on hold.

On a more positive note, new candidate OTM materials systems have recently shown sufficient promise in parallel OTM development programs at Praxair and partners to consider them for the integrated combustion application. The Tarrytown experimental combustion facilities have now been re-commissioned in Tonawanda. More resources will be allocated to this program during the $2^{\text {nd }}$ half of 2003 .

The economics of the process continue to appear to be very attractive. Without sequestration, efficiency improvements of $14 \%$ are possible with fuel savings of over $\$ 450,000 /$ year on a $100,000 \mathrm{lb} / \mathrm{hr}$ steam boiler. This represents potential domestic energy savings of over $\$ 600$ million/yr @ \$3/MMBTU. This should allow the economic introduction of the technology and $\mathrm{CO}_{2}$ emissions savings without sequestration. Further $\mathrm{CO}_{2}$ capture and compression costs are still estimated to be significantly less than $\$ 10 /$ ton carbon. 


\section{E. $\underline{\text { References }}$}

Thompson et. al, "Advanced Oxyfuel Boilers and Process Heaters for Cost-Effective $\mathrm{CO}_{2}$ Capture and Sequestration", Quarterly Technical Update Report for US DOE Award No. DEFC26-01NT41147, June 2002.

Thompson et. al, "Advanced Oxyfuel Boilers and Process Heaters for Cost-Effective $\mathrm{CO}_{2}$ Capture and Sequestration", Quarterly Highlights Report for US DOE Award No. DE-FC2601NT41147, October 2002.

Thompson et. al, "Advanced Oxyfuel Boilers and Process Heaters for Cost-Effective $\mathrm{CO}_{2}$ Capture and Sequestration”, Quarterly Highlights Report for US DOE Award No. DE-FC2601NT41147, December 2002. 